\title{
JURNALISME DAN SENI \\ SEBAGAI JALAN PERDAMAIAN
}

\author{
David Krisna Alka
}

Rudi Fofid tak menyimpan dendam atas peristiwa masa lalu. Ayah dan dua kakak perempuannya dibunuh saat konflik terjadi. Ketika konflik mulai memanas di Bacan, ayah dan keluarganya memilih tidak mengungsi, karena merasa sudah sehati dan sejiwa dengan daerah itu. Ayahnya sudah diperingatkan oleh para tetangga, akan terjadi serangan ke rumahnya. Sang ayah bersikukuh tidak mengungsi, namun menyuruh keluarga yang lain untuk segera pergi dari rumah. Hingga kemudian, ayah dan kakaknya terbunuh. Saat kejadian itu, Rudi Fofid sedang berada di kota Tual, Provinsi Maluku. Rudi tak menyimpan dendam atas peristiwa masa lalu itu. Bahkan tidak menangis berbulanbulan. Ia hanya merasa tak ada kesempatan berkumpul lagi. Ia memahami bahwa dalam konflik, pelaku pembunuhan juga didesain untuk menjadi pembunuh. Dalam hal itu, menurut Rudi, mereka, para pelaku pembunuhan adalah juga korban. Rudi Fofid adalah keturunan asli Kei, Desa Ngilngof. Desa Ngilngof terletak di Kabupaten Maluku Tenggara. Mayoritas penduduknya beragama Katolik. Ayah Rudi adalah seorang mantan tentara KNIL yang akhirnya bergabung dengan Tentara Republik Indonesia. Setelah pensiun sebagai tentara, Ayah Rudi memilih berkebun. Keadaan geografis Kepulauan Kei yang didominasi batu karang dan tak sesuai untuk bercocok tanam, memaksa Ayah Rudi untuk memboyong keluarganya pindah ke Bacan, Kabupaten Halmahera Selatan, Maluku Utara. Rudi yang terbiasa tinggal di 
Kepulauan Kei dengan penduduk mayoritas Katolik, harus bertetangga dengan penduduk Bacan yang mayoritas Islam.

Rudi menamatkan masa SD hingga SMP di Bacan. Saat SMA, Rudi pindah ke Ambon dan tinggal dengan penduduk yang mayoritas Kristen Protestan. Setelah dewasa, Rudi menyadari, masa kecilnya yang hidup berpindah-pindah dan tinggal bertetangga dengan orang yang berbeda agama, membentuk karakter baru dalam perjalanan hidupnya. Rudi kemudian mengenal seorang Pastor Jan van de Made MSC yang saat itu menjabat sebagai Ketua Komisi Hubungan Antar Agama dan Kepercayaan (HAK) di Keuskupan Amboina. Karena bergaul dengan Pastor tersebut, Rudi kemudian sering diajak untuk menghadiri kegiatan-kegiatan dialog antar agama. Selain dari orangtua, kegiatan itu kemudian memberi pandangan baru bagi Rudi. Tahun 1985, karena kekurangan pastor untuk melayani ibadah di Paroki, Rudi dkk dari Perhimpunan Mahasiswa Katolik Republik Indonesia (PMKRI) Cabang Ambon dilatih untuk memimpin ibadah dan membantu pastor melayani paroki yang ada di wilayah kecamatan Teluk Ambon. Inilah pertama kali Rudi terjun bebas dalam masyarakat. Rudi dkk melayani wilayah kecil di Dusun Telaga Kodok Desa Hitu, di utara Pulau Ambon, yang mayoritas penduduknya adalah Muslim. Rudi kemudian bersosialisasi dengan masyarakatnya dan turun langsung pada penanganan masalahmasalah sosial, seperti nikah beda agama, kekerasan dalam rumah tangga, kekerasan dalam gereja, dan lain sebagainya.

\section{“Mendamaikan" jurnalisme}

Awal mula menjadi wartawan, Rudi belajar dari keuskupan saat menangani majalah Gereja, dan kemudian menjadi redaktur Koran Kampus saat itu. Hal ini membuat Rudi dengan mudah masuk dan menjadi wartawan profesional. Saat menjadi wartawan di Harian Suara Maluku, Rudi menjadi wartawan olahraga dengan fokus pada sepakbola. Rudi pun kemudian akrab dengan Desa Tulehu, desa dengan mayoritas penduduk Islam yang banyak melahirkan pemain sepakbola Nasional saat ini. Pada tahun 1999 konflik Ambon terjadi, hanya satu surat kabar yang beredar di Maluku, yakni Suara Maluku. Suara Maluku merupakan koran harian yang saat awal konflik terjadi, komposisi redaksinya mayoritas beragama Kristen sementara bagian distribusi dan percetakan didominasi oleh pegawai yang beragama Islam. Saat 
itu semua wartawan kebingungan karena konflik mensegregasi wilayah pemukiman berdasarkan agama. Wartawan Kristen tidak meliput di kawasan Islam dan begitupun sebaliknya. Bias informasi ini menjadikan berita yang tidak berimbang, karena nyaris tanpa klarifikasi. Rudi dan kawan-kawan wartawan, yang sadar akan kekacauan informasi saat itu, kemudian berinisiatif melahirkan sebuah media alternatif untuk mengklarifikasi isu-isu media mainstream. Selain itu, saat konflik terjadi, banyak sekali posko-posko kemanusiaan yang hadir dari komunitas agama yang bertikai. Posko-posko ini turut membantu mengacaukan situasi karena hadir sebagai posko kemanusiaan yang melayani umat agama tertentu saja. Rudi dan kawan-kawan wartawannya kemudian berinisiatif untuk mendirikan posko Tim Relawan untuk Kemanusiaan.

Setahun setelah itu, Rudi dan kawan-kawan kemudian mendirikan Maluku Media Center (MMC). Sebuah organisasi yang menjadi rumah bersama para wartawan beda agama. MMC menerbitkan media alternatif untuk membantu memberi sudut pandang baru dari informasi media mainstream seperti Kompas, Republika atau Suara Pembaharuan. Tahun 2003 setelah Suara Maluku keluar dari Jawa Pos Group, Rudi kembali bergabung. Ambon Ekspress, koran baru yang lahir pasca konflik sebagai bagian dari Jawa Pos Group. Ambon Ekspress dan juga Suara Maluku berusaha keluar dari stigma yang mereka buat sendiri saat konflik. Menurut Rudi, jika hari ini ada media yang tidak menulis berdasarkan prinsip jurnalisme damai, maka media tersebut akan diolokolok. Media di Maluku tidak lagi tersegregasi berdasarkan agama. Unsur keberimbangan harus ditegakkan. Kerja-kerja jurnalisme damai yang dilakukan Rudi Fofid ditegaskan oleh M. Aziz Tunny, Mantan Wartawan dan Ketua KPID Maluku. Aziz Tunny berjumpa dengan Rudi pada akhir tahun 2002 di kantor MMC. MMC saat itu merupakan rumah bersama para wartawan. Sebab kantor media di kota Ambon telah tersegregasi berdasarkan agama masing-masing. Saat konflik berlangsung, ketika orang sedang sibuk berperang dan tak memikirkan kemungkinan perdamaian, Rudi telah menjadi anggota Tim Relawan Kemanusiaan. Rudi dan istrinya sangat berani menerobos barikade batas komunitas Muslim dan Kristen untuk memberikan bantuan.

Menurut Aziz, Rudi juga memiliki kisah yang kelam dalam konflik. Ayah kandung dan kakak perempuannya terbunuh saat konflik di Bacan, Maluku Utara. Pandangan Aziz, dia tak melihat sedikit pun 
dendam dalam jiwa Rudi ketika tahu bahwa orang tuanya dibunuh oleh komunitas muslim saat konflik berkecamuk. Saat konflik, Aziz sebagai wartawan muda yang mengawali karir Jurnalistik banyak belajar tentang Jurnalisme Damai dari Rudi. Ketika bekerja bersama Rudi di MMC, Aziz dan Rudi juga menggagas sebuah media online yang khusus memproduksi feature-feature humas berperspektif jurnalisme damai. Rudi menurut Aziz, sangat mudah diterima semua kalangan. Orang-orang mengenal sosok Rudi sebagai pribadi yang sederhana dan dihormati. Orangorang muda yang dibimbing Rudi kemudian menjadi agen-agen perdamaian. Aziz memberi contoh misalnya, saat terjadi bentrok 11 september 2011, muncul gerakan yang diberi nama Provokator Damai. Gerakan hadir untuk counter isuisu negatif yang berkembang di masyarakat dengan menggunakan medium media sosial. Bagi Aziz, Rudi adalah sosok yang merdeka dan berani dalam menyampaikan nilai-nilai yang dianggapnya benar. Rudi tidak segan mengkritik pemerintah bahkan militer secara terbuka, baik melalui pernyatan maupun melalui ekspresi seni dan kata, seperti puisi dan esai.

Dalam pandangan kontributor Majalah Kartini, Sekretaris MMC, dan Aktivis Perempuan, Saswaty Matakena, sejak konflik banyak orang telah mengenal Rudi Fofid. Rudi saat itu adalah jurnalis senior di harian Suara Maluku. Saat konflik berlangsung, media massa, terutama koran memainkan peran penting dalam memperparah konflik. Media saat itu dipisahkan berdasarkan kepentingan agama masing-masing. Pemberitaan yang tidak berimbang itu membuat kondisi konflik semakin parah. Saat itu Rudi bersama beberapa rekan wartawan senior mendirikan MMC, sebuah rumah bersama jurnalis di Maluku. Rudi ditunjuk menjadi Koordinator saat itu. Saat ini posisi Rudi adalah Ketua Komite Pengarah MMC. Pasca konflik, Saswaty melihat Rudi agak bergeser ke dunia seni dan sastra. Rudi menyediakan wadah bagi anak-anak muda untuk berkreasi dan berkesenian. Rudi mendidik anak-anak muda pasca konflik untuk mencintai dunia sastra. Saswaty melihat banyak perubahan anakanak jalanan yang didik oleh Rudi. Rudi juga mendorong anak-anak ini untuk berjiwa wirausaha, misalnya, Workshop Coffee yang saat ini sedang hits di anak muda Kota Ambon. Elsya Syauta Latuheru, Aktivis Perdamaian dan Perempuan, Yayasan Parakletos, mengenal Rudi jauh sebelum bekerja sebagai aktivis perdamaian. Lebih dari dua dekade, Elsye telah mengenal dan bekerjasama dan Rudi. Saat konflik 11 September 2011 terjadi, Elsye 
bersama-sama Rudi menggalang anakanak muda Kota Ambon untuk menjadi relawan perdamaian dan turun ke desa-desa yang menjadi perbatasan dua komunitas bertikai dengan membawa Kopi. Gerakan ini kemudian bernama Coffee Badati. Bagi Elsye, dalam bidang sastra Rudi dapat disebut sebagai Maestro di Maluku. Rudi menggunakan medium itu untuk mengumpulkan anak muda kreatif dan melatih talenta mereka. Menurut Elsye, Rudi tidak membedakan orang dari sisi gender. Dia memandang tiap pribadi mempunyai hak dan kesempatan yang sama.

\section{Seni sebagai jalan damai}

Dalam dunia seni dan sastra, Rudi aktif ketika 2009 mulai mengumpulkan anak-anak yang senang pada puisi dan sastra. Rudi bertemu dengan M. Irfan Ramli pada sebuah ajang lomba puisi. Rudi, Irfan, dan juga Morika Tetelepta kemudian mendirikan Bengkel Sastra Maluku. Bengkel Sastra Maluku mengumpulkan para anak muda berbeda agama untuk sama-sama berkreasi dalam seni sastra. Banyak anak-anak muda ini, kini telah sukses di bidang mereka masing-masing. Rudi, menjadi role model bagi anak muda di Maluku karena menggunakan medium seni atau sastra sebagai sarana mempertemukan anakanak muda yang tersegregasi pasca konflik. Roesda Leikawa, aktivis Perempuan, dan aktif di Ema Bergerak bersama Rudi Fofid. Mengenal Rudi sejak tahun 2013 saat berinteraksi di Komunitas Bengkel Sastra Maluku. Bagi Roesda, Rudi sudah seperti bapak, teman, dan saudara. Rudi mengajarkan banyak hal pada Roesda, terutama mengenai sastra.

Saat terjadi Konflik antar warga di Desa Mamala dan Desa Morela pada tahun 2014, Roesda bersama Rudi memfasilitasi pemudapemuda di kedua desa untuk bertemu dan menggelar kegiatan bersama-sama untuk perdamaian. Tak kurang 500 orang hadir dalam acara pentas sastra tersebut. Citra Dewi, Mahasiswa FISIP Unpatti Ambon, Pegiat Komunitas Lentera, mengatakan, peran Rudi Fofid bagi dunia sastra terutama puisi sangat besar di Maluku. Dalam pandangan Citra, dalam membuat karya sastra, Rudi selalu memasukan unsur-unsur perdamaian, toleransi, dan pluralisme. Rudi juga membantu anak muda lintas agama untuk berinteraksi dalam panggung sastra yang digelarnya tiap minggu, yaitu Mimbar Sastra. Embong Salampessy, Jurnalis Foto Antara, Gatra, dan Aktivis Perdamaian, mengenal Rudi saat bekerja sebagai relawan 
di awal konflik Maluku terjadi tahun 1999. Walau berbeda dalam penggunaan medium untuk mengkampanyekan perdamaian, Rudi dan Embong pernah bekerja sama. Menurut Embong, media mainstream saat konflik berlangsung di tahun 1999, tidak memberi ruang bagi tematema perdamaian. Saat itu, Rudi tampil dengan medium sastra, dalam hal ini puisi untuk mengkampanyekan perdamaian. Rudi mengajak anak-anak muda menggelar Trotoart, sebuah panggung seni dan musik yang berbasis di sebuah jalan raya kota Ambon. Rudi selalu berusaha untuk turut andil dalam gerakan memprovokasi damai. Rudi menurut Embong, bekerja secara sukarela dan tanpa dibayar. Hal ini dia lakukan secara konsisten hingga sekarang.

Orang-orang muda Ambon yang berteman dan bersahabat dengan Rudi Fofid akrab menyapanya dengan sebutan Opa. Salah satunya adalah Pierre Ajawaila, Aktivis Paparisa Ambon Bergerak. Menurut Pierre, Opa banyak membantu komunitas-komunitas orang muda di Ambon. Selain komunitas sastra, Opa juga menjadi penasehat Komunitas HipHop Ambon. Pierre sudah banyak mendengar cerita tentang kerja-kerja perdamaian Opa sejak konflik tahun 1999. Opa memiliki jejaring luas di kampung-kampung. Bukan hanya komunitas seni, Opa sekarang juga aktif kegiatan lingkungan dan pencinta alam. Opa bisa masuk di semua komunitas dan jejaring orang muda. Banyak yang dilakukan Opa untuk menyatukan orang-orang muda di Ambon. Mengenai luasnya pergaulan Rudi Fofid dalam dunia sastra, ada kisah menarik. Saat itu Rudi dirawat di sebuah rumah sakit karena kecelakaan bermotor. Penyair D. Zawawi Imron datang menjenguk. Ketika Rudi terbaring, D. Zawawi Imron membacakan satu puisi yang khusus dibuatnya untuk Rudi. Tatkala D. Zawawi Imron membacakan puisi, kedua bola mata Rudi menerang, air matanya berlinang. Ya, begitulah puisi, mendamaikan masa dan kita, tatkala mengalami jatuh dan terluka, sedih maupun bahagia. Dan, Rudi Fofid percaya pada pendapat banyak penyair. Ketika politik merusak, puisi membangun. Ketika rakyat dibungkam, puisi harus bicara.

Profil ini disarikan dari laporan lapangan yang disusun oleh David Krisna Alka 